\title{
Dexamethasone Regulation of Glycosaminoglycan Synthesis in Cultured Human Skin Fibroblasts \\ Similar Effects of Glucocorticoid and Thyroid Hormones
}

Terry J. Smith

Section of Metabolic and Endocrine Disease, Department of Medicine, Medical College of Georgia and Veterans

Administration Medical Center, Augusta, Georgia 30910

bstract. The effects of dexamethasone on glycosaminoglycan accumulation were examined in confluent human skin fibroblasts in vitro. The glucocorticoid consistently inhibited the incorporation of either $\left[{ }^{3} \mathrm{H}\right]$ acetate or $\left[{ }^{3} \mathrm{H}\right]$ glucosamine into hyaluronate when added to culture medium $72 \mathrm{~h}$ before harvest. This effect was half-maximal at $\sim 1 \mathrm{nM}$ and maximal at 5-10 $\mathrm{nM}$. Inhibition occurred within $5 \mathrm{~h}$ of hormone addition and was near maximal by $25 \mathrm{~h} .11 \alpha$-hydrocortisone (10 $\mathrm{nM})$, deoxycorticosterone (10 $\mathrm{nM})$, and progesterone $(100 \mathrm{nM})$ failed to inhibit this accumulation; however, progesterone $(2 \mu \mathrm{M})$, a known glucocorticoid antagonist at high concentration, could attenuate the response to dexamethasone by $57 \%$. Cultures were pulselabeled and then chase incubated for up to $68 \mathrm{~h}$. No difference in the rate of $\left[{ }^{3} \mathrm{H}\right]$ hyaluronate degradation could be demonstrated in steroid-treated cultures. Triiodothyronine $\left(\mathrm{T}_{3}\right)$ can also inhibit synthesis of hyaluronate in fibroblasts (Smith, T. J., Y. Murata, A. L. Horwitz, L. Philipson, and S. Refetoff, 1982, J. Clin. Invest., 70:1066-1073). Both $T_{3}$ and dexamethasone could inhibit glycosaminoglycan accumulation in a dose-dependent manner. Maximal $T_{3}$ effects were achieved at 1 $\mathrm{nM}$ and those of dexamethasone at $10 \mathrm{nM}$. Saturating concentrations of $T_{3}$ and dexamethasone added alone inhibited $\left[{ }^{3} \mathrm{H}\right]$ hyaluronate by 54 and $49 \%$, respectively. When both hormones were added, accumulation was inhibited by $84 \%$. Dexamethasone inhibits $\left[{ }^{3} \mathrm{H}\right]$ hyal-

\footnotetext{
Portions of this work were presented at the VIIth International Congress of Endocrinology, Quebec, Canada, 1-7 July 1984. Address reprint requests to Dr. Smith, Endocrine Section (111B), Veterans Administration Medical Center, Augusta, GA 30910. 1984. Received for publication 9 April 1984 and in revised form 9 August
}

J. Clin. Invest.

(c) The American Society for Clinical Investigation, Inc. $0021-9738 / 84 / 12 / 2163 / 14 \quad \$ 1.00$

Volume 74, December 1984, 2157-2163 uronate accumulation in a time, dose-dependent, and stereo-specific manner. The rate of glycosaminoglycan degradation was unaffected, and thus, the steroid inhibited the rate of macromolecular synthesis. This effect was likely mediated through glucocorticoid receptors. Hyaluronate synthesis in skin fibroblasts appears to be regulated by both glucocorticoids and $T_{3}$ through different pathways.

\section{Introduction}

Glycosaminoglycans (GAG) ${ }^{1}$ are complex sugars that comprise dermal ground substance (1). While the mechanisms involved in the synthesis and the biological role of GAG remain controversial, some human diseases are associated with an abnormal accumulation of these substances: Marfan's syndrome (2), Graves' disease (3), and hypothyroidism (4).

Human skin fibroblasts are easily obtained, can be propagated in tissue culture, and synthesize large amounts of GAG, of which hyaluronate (HA) predominates (5). Abnormal GAG accumulation has been reported in fibroblast cultures from patients with osteogenesis imperfecta (6), Marfan's syndrome (7), and rheumatoid arthritis (8). My colleagues and I demonstrated recently that $3,3^{\prime}, 5$ triiodothyronine $\left(T_{3}\right)$, the biologically active thyroid hormone, could inhibit accumulation of HA in skin fibroblast cultures incubated in medium supplemented with thyroid hormone-depleted serum (9). This inhibition was both time- and dose-dependent, saturable at a physiologic concentration of $T_{3}$, and was a consequence of a decreased rate of synthesis rather than an increased rate of GAG degradation (10). The skin fibroblast culture depleted of thyroid hormone may thus be an in vitro model of human myxedema.

1. Abbreviations used in this paper: Dex, dexamethasone (1,4 pregnadien9-fluoro-16 $\alpha$-methyl-11 $\beta, 17 \alpha, 21$-triol-3,20-dione); DOC, 11-deoxycorticosterone (21-hydroxy-4-pregnene-3,20-dione); GAG, glycosaminoglycan; HA, hyaluronic acid; $11 \alpha$-hydrocortisone, epicortisol $(11 \alpha, 17,21$ trihydroxy-4-pregnene-3,20-dione); $T_{3}, 3,3$,5-L-triiodothyronine; $T_{4}$, thyroxine, 3,3',5,5'-L-tetraiodothyronine; Tx-Bs, serum from thyroidectomized calves. 
Glucocorticoids, like thyroid hormone, are capable of influencing human skin fibroblasts in vitro by altering cellular proliferation (11), collagen biosynthesis (12), and regulating specific protein synthesis (13). While the observation that glucocorticoids can inhibit GAG accumulation has been made previously $(14,15)$, little is known about the nature of this inhibition or whether GAG synthesis or degradation is altered.

The current report describes results of studies designed to determine the kinetics, specificity, and mechanism involved in the inhibition of HA accumulation by dexamethasone (Dex), a potent synthetic glucocorticoid, and to compare this inhibition with that of $T_{3}$. Such information may be useful in understanding hormonal regulation of complex sugar synthesis in human skin fibroblasts.

\section{Methods}

\section{Materials}

$\left[{ }^{3} \mathrm{H}\right]$ Acetic acid $\left(2.8 \mathrm{Ci} / \mathrm{mmol}\right.$ sp act) and $\left[{ }^{3} \mathrm{H}\right]$ glucosamine (19.7 $\mathrm{Ci} / \mathrm{mmol}$ ) were purchased from New England Nuclear, Boston, MA, and $\left[{ }^{3} \mathrm{H}\right]$ leucine $(50 \mathrm{Ci} / \mathrm{mmol})$ was obtained from ICN Pharmaceuticals, Irvine, CA. Chondroitin sulfate, dexamethasone, progesterone, triiodothyronine, and pronase were purchased from Sigma Chemical Co., St. Louis, MO, and deoxycorticosterone and $11 \alpha$-hydrocortisone were from Steraloids, Wilton, NH. Hyaluronate was extracted from human umbilical cord. Streptomyces hyaluronidase was obtained from Miles Laboratories, Inc., Elkhart, IN. All other chemicals used were of the highest purity commercially available.

\section{Procedures}

Cell culture. Human skin fibroblasts were obtained from American Type Culture Collection, Rockville, MD, and propagated in Eagle's minimal essential medium supplemented with Earle's salts, glutamine, penicillin/streptomycin, and amphotericin B, and enriched with $10 \%$ fetal calf serum. Cells were plated on $60-\mathrm{mm}$ diam plastic petri dishes covered with $4 \mathrm{ml}$ medium that was changed every 3-4 d. Initial plating density ranged from $\sim 400,000$ to 600,000 cells/plate and cultures were allowed to grow to confluence in a $37^{\circ} \mathrm{C}$, humidified $5 \%$ $\mathrm{CO}_{2}$ incubator before any hormonal manipulations. Hormones were added as concentrates dissolved in $95 \%$ ethanol. Control cultures were treated with equivalent volumes of diluent. Some experiments involved shifting cultures to medium supplemented with $10 \%$ thyroidectomized calf serum (Tx-Bs; Rockland Farms, Gilbertsville, PA). This serum contained $<0.3 \mu \mathrm{g} / \mathrm{dl}$ thyroxine $\left(\mathrm{T}_{4}\right)$ and $<20 \mathrm{ng} / \mathrm{dl} \mathrm{T}_{3}$; the lower limits of sensitivity of respective radioimmunoassays kindly performed by Dr. N. H. Scherberg, University of Chicago. Hormone-treated cultures were usually incubated for $48 \mathrm{~h}$ and then shifted to the same medium to which either $\left[{ }^{3} \mathrm{H}\right]$ acetic acid $(5-10 \mu \mathrm{Ci} / \mathrm{ml})$ or $\left[{ }^{3} \mathrm{H}\right]$ glucosamine $(5 \mu \mathrm{Ci} / \mathrm{ml})$ was added and allowed to label for $16-24 \mathrm{~h}$. The labeling period was shortened to $5 \mathrm{~h}$ in the time course study and to $10 \mathrm{~h}$ in the pulse-chase studies. The chase incubation in the later study utilized unlabeled medium containing $1 \mathrm{mM}$ sodium acetate. Cultures were incubated with $\left[{ }^{3} \mathrm{H}\right]$ leucine $(5 \mu \mathrm{Ci} / \mathrm{ml}$ medium $)$ in protein synthesis studies.

Quantitation of $\left[{ }^{3} \mathrm{H}\right] \mathrm{GAG}$ and $\left[{ }^{3} \mathrm{H}\right] \mathrm{HA}$ accumulation. Culture media were quantitatively collected and cell layers washed with phosphatebuffered saline. Cell layers were then solubilized in $0.1 \mathrm{~N} \mathrm{NaOH}$ and scraped off the substratum with a rubber policeman. Following the collection of an aliquot for protein determination by the method of Lowry et al. (16), the cell layers, media, and wash were recombined and digested with pronase $(1 \mathrm{mg} / \mathrm{ml})$ in a $100-\mathrm{mM}$ Tris buffer, $\mathrm{pH}$ 8.0 , at $50^{\circ} \mathrm{C}$ overnight in the presence of hyaluronate and chondroitin sulfate ( $250 \mu \mathrm{g}$ each), which were added as carriers. After cooling on ice, samples were precipitated with trichloroacetic acid (TCA) $(5 \%$ wt/ vol final concentration) for $30 \mathrm{~min}$ and were then centrifuged at 10,000 g. The supernatant was dialyzed extensively against water to remove free label and an aliquot was counted by liquid scintillation spectrometry and defined as total GAG. In some experiments, postdialysis samples were lyophilized to dryness and subjected to streptomyces hyaluronidase digestion as previously described (9). Approximately $90 \%$ of the total $\left[{ }^{3} \mathrm{H}\right] \mathrm{GAG}$ was hyaluronidase digestible, irrespective of hormone treatment. In early experiments, uronic acid content in postdialysis samples

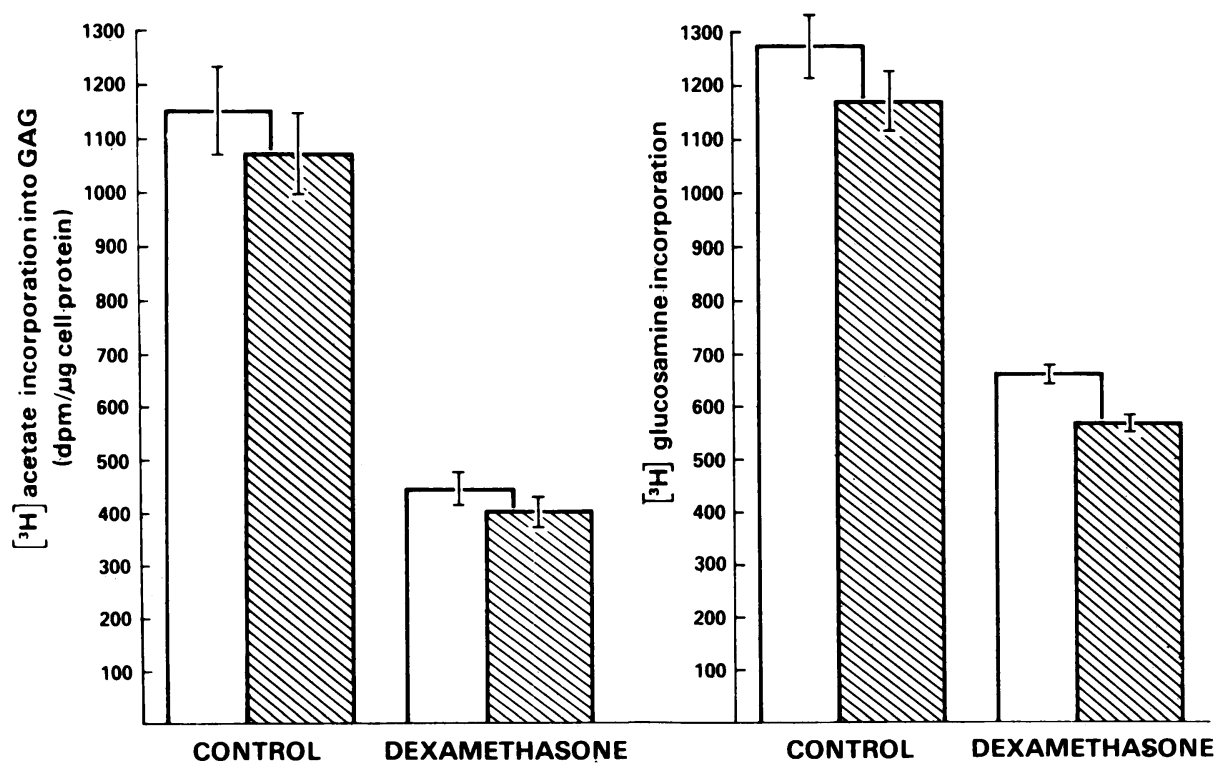

Figure 1. Effect of Dex on the incorporation of $\left[{ }^{3} \mathrm{H}\right]$ acetate and $\left[{ }^{3} \mathrm{H}\right]$ glucosamine into GAG (ם) and HA (घ). Confluent cultures were treated with Dex $(100 \mathrm{nM})$ or diluent for $48 \mathrm{~h}$, shifted to the same medium supplemented with either $\left[{ }^{3} \mathrm{H}\right]$ acetate or $\left[{ }^{3} \mathrm{H}\right]$ glucosamine $(5 \mu \mathrm{Ci} / \mathrm{ml})$ for an additional $1 \mathrm{~d}$, and then, harvested. Each column represents the mean of duplicate plates \pm range from one representative experiment. Incorporation is expressed either prior to (total GAG) or following streptomyces hyaluronidase digestion (hyaluronate). 


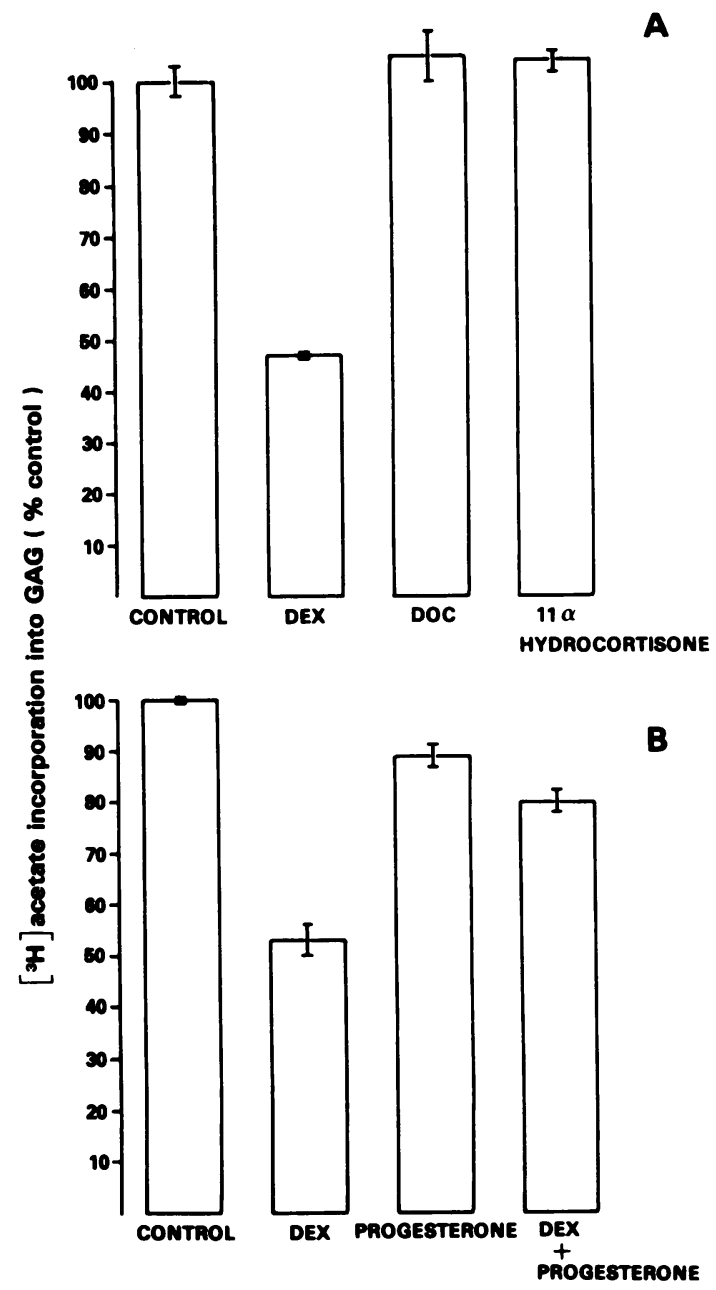

Figure 2. (A) Effects of Dex, DOC, and $11 \alpha$-hydrocortisone on $\left[{ }^{3} \mathrm{H}\right] \mathrm{GAG}$ accumulation. Cultures were grown to confluence, shifted to medium enriched with a steroid $(10 \mathrm{nM})$ or diluent alone (control) for $2 \mathrm{~d}$, and then, labeled with $\left[{ }^{3} \mathrm{H}\right]$ acetate $(5 \mu \mathrm{Ci} / \mathrm{ml}$ medium) for an additional $1 \mathrm{~d}$. (B) Effects of Dex and progesterone on $\left[{ }^{3} \mathrm{H}\right] \mathrm{GAG}$ accumulation. Cultures were grown as in $A$ and treated with either Dex $(1 \mathrm{nM})$, progesterone $(2 \mu \mathrm{M})$, both hormones, or diluent alone (control). Data are expressed as the mean \pm SEM of triplicate cultures from one representative experiment.

was determined by the method of Dische (17). Intersample recoveries were uniform. The digested material was separated by Sephadex G-50 (Pharmacia Fine Chemicals, Inc., Piscataway, NJ) column chromatography using a pyridine acetate buffer, $\mathrm{pH} 5.8$, as the eluant. Details concerning the recoveries have been published elsewhere $(9,10)$.

Data are expressed either as mean \pm range of determinations in duplicate cultures or as the mean \pm SEM of triplicate cultures with statistical significance analyzed by Student's $t$ test.

\section{Results}

The addition of Dex to confluent human skin fibroblast cultures resulted in a marked inhibition of both $\left[{ }^{3} \mathrm{H}\right] \mathrm{GAG}$ and $\left[{ }^{3} \mathrm{H}\right] \mathrm{HA}$ accumulation when present for $72 \mathrm{~h}$ before harvest (Fig. 1). Dex (100 nM) inhibited both $\left[{ }^{3} \mathrm{H}\right]$ acetate and $\left[{ }^{3} \mathrm{H}\right]$ glucosamine incorporation into GAG by 62 and $50 \%$, respectively (Fig. 1). The absolute magnitude of this inhibition varied from 40 to $83 \%$ in other experiments. Lack of substrate specificity suggested that the inhibition of accumulation was not a consequence of precursor pool shifts. Results were similar whether expressed per milligram protein or cell number.

The dose dependence of the Dex inhibition was established by incubating cultures with various concentrations of the steroid (range 0.1-1,000 nM). A half-maximal response occurred at $1 \mathrm{nM}$ and was saturable at 5-10 nM. Additions of up to 100 -fold higher concentration had no further effects.

To assess whether the observed effects of Dex on $\left[{ }^{3} \mathrm{H}\right] \mathrm{GAG}$ accumulation could be produced by nonglucocorticoid steroidal hormones, some cultures were treated with Dex (10 nM); deoxycorticosterone (DOC, $10 \mathrm{nM}$ ), a mineralocorticoid devoid of glucocorticoid activity; or $11 \alpha$-hydrocortisone (10 nM), an inactive steroid. As Fig. $2 A$ demonstrates, neither DOC nor $11 \alpha$-hydrocortisone inhibited GAG accumulation when added at concentrations eliciting near maximal Dex inhibition. Progesterone, a steroid that has been previously shown to partially antagonize the action of glucocorticoids (18), also failed to influence the rate of $\left[{ }^{3} \mathrm{H}\right] \mathrm{GAG}$ accumulation at similar concentrations (data not shown). High concentrations of progesterone $(2 \mu \mathrm{M})$, however, inhibited [ ${ }^{3} \mathrm{H}$ ]GAG slightly $(11 \%, P<0.005)$ compared with Dex $(1 \mathrm{nM}, 47 \%, P<0.001)$ (Fig. $2 B$ ). When both hormones were added at these respective concentrations, the Dex effect on $\left[{ }^{3} \mathrm{H}\right] \mathrm{GAG}$ accumulation was attenuated by $57 \%(P<0.005)$ (Fig. $2 \mathrm{~B})$.

Fig. 3 demonstrates the time course of Dex inhibition of $\left[{ }^{3} \mathrm{H}\right] \mathrm{GAG}$ accumulation. When the labeling period was shortened, Dex inhibited $\left[{ }^{3} \mathrm{H}\right.$ ]acetate incorporation within $5 \mathrm{~h}$ of hormone addition. There was a further decrease in accumulation over the duration of the study until near maximal effects were achieved at $25 \mathrm{~h}$. Since confluence had been reached prior to the addition of hormone, protein content did not vary among plates.

To determine whether the effect of Dex on $\left[{ }^{3} \mathrm{H}\right] \mathrm{GAG}$ accumulation was a result of an inhibition of cellular uptake of labeled precursor or was due to a more specific effect on macromolecular metabolism, cultures were incubated under conditions that yielded a near maximal Dex response. Cell layers were then trypsinized, washed extensively, and analyzed for $\left[{ }^{3} \mathrm{H}\right]$ acetate uptake. Control cell layers accumulated $45,600 \pm 4,400 \mathrm{dpm} / 100,000$ cells (mean \pm SEM, $n=3$ ) compared with $48,200 \pm 1,200 \mathrm{dpm} / 100,000$ cells in Dex-treated cultures (NS). Alterations of cellular uptake, therefore, apparently were not responsible for the glucocorticoid inhibition of $\left[{ }^{3} \mathrm{H}\right] \mathrm{GAG}$ accumulation. Dex also failed to influence the incorporation of $\left[{ }^{3} \mathrm{H}\right]$ leucine into TCA-precipitable material. In a study where $\left[{ }^{3} \mathrm{H}\right] \mathrm{GAG}$ accumulation was inhibited $58 \%$, Dex-treated cultures retained 20,979 $\pm 1,045 \mathrm{dpm}\left[{ }^{3} \mathrm{H}\right]$ leucine/ $\mu \mathrm{g}$ protein (mean $\pm \mathrm{SEM}, n=3$ ) in TCA-insoluble material compared with $21,283 \pm 565 \mathrm{dpm} / \mu \mathrm{g}$ protein in controls (NS). 


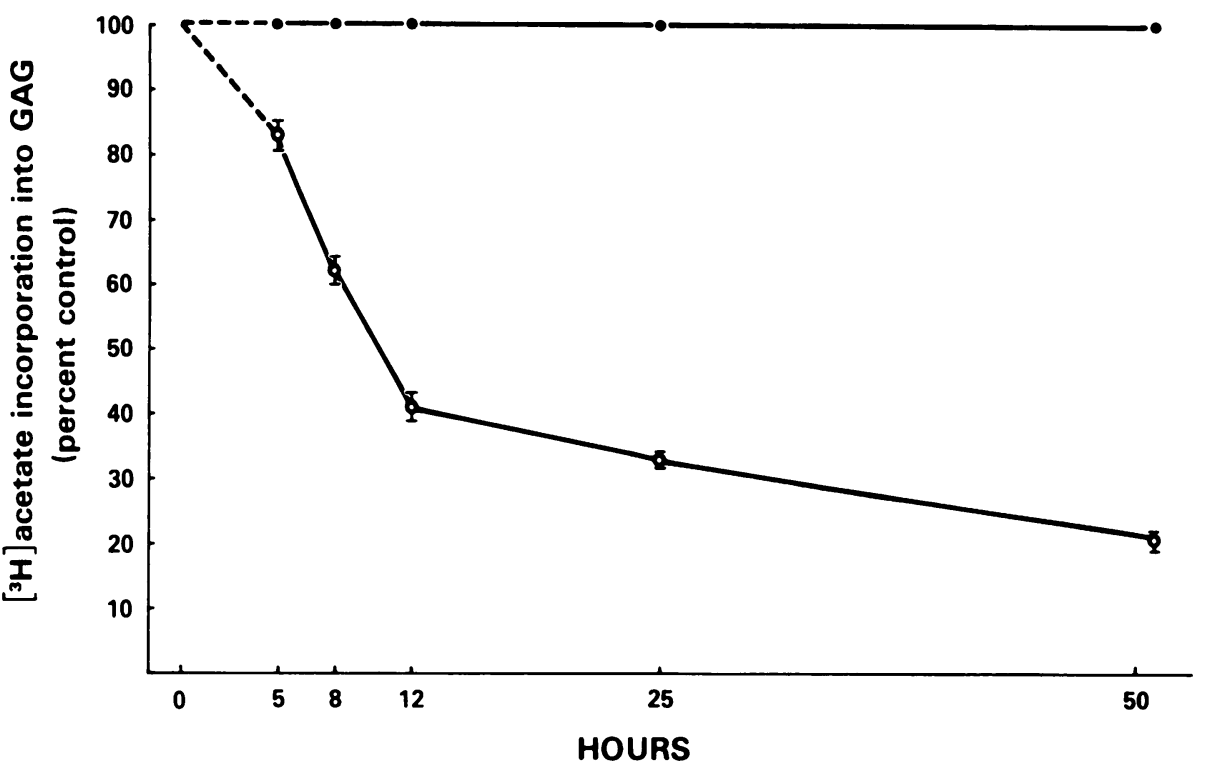

Figure 3. Time course of the effect of Dex on $\left[{ }^{3} \mathrm{H}\right] \mathrm{GAG}$ accumulation. Confluent cultures were incubated with Dex $(100 \mathrm{nM})(0)$ or diluent $(\bullet)$ for the various durations of time indicated along the abscissa. All cultures were labeled for $5 \mathrm{~h}$ before harvest. Each datum point represents the mean \pm range from a single representative experiment.
To assess whether the observed inhibition by Dex of $\left[{ }^{3} \mathrm{H}\right] \mathrm{GAG}$ and $\left[{ }^{3} \mathrm{H}\right] \mathrm{HA}$ accumulation was a consequence of an altered rate of degradation, cultures were preincubated without or with the hormone (100 $\mathrm{nM})$ and then pulse-labeled $(10 \mathrm{~h})$ followed by a chase incubation for various intervals in media containing unlabeled sodium acetate $(1 \mathrm{mM})$. The results shown in Table I suggest that there was no effect of Dex on the degradation rate of either $\left[{ }^{3} \mathrm{H}\right] \mathrm{GAG}$ or $\left[{ }^{3} \mathrm{H}\right] \mathrm{HA}$ over the duration of the chase incubation (68 h), as would have been reflected by a change in the ratio of incorporation in cultures incubated with Dex vs. controls. In fact, there was no evidence of ${ }^{3} \mathrm{H}$-labeled macromolecular degradation over the course of

Table I. Effect of Dex on $\left[{ }^{3} H\right] G A G$ and

$\left[{ }^{3} \mathrm{H}\right] H A$ Degradation in a Pulse-Chase Experiment

\begin{tabular}{lllll}
\hline & \multicolumn{4}{l}{ Duration of chase $(h)$} \\
\cline { 2 - 5 } & 14.5 & 23 & 40 & 68 \\
\hline$\left[{ }^{3} \mathrm{H}\right] \mathrm{GAG}\left(\frac{+ \text { Dex }}{- \text { Dex }}\right)$ & 0.50 & 0.48 & 0.50 & 0.51 \\
{$\left[{ }^{3} \mathrm{H}\right] \mathrm{HA}\left(\frac{+ \text { Dex }}{- \text {-Dex }}\right)$} & 0.49 & - & - & 0.50
\end{tabular}

Confluent cultures were incubated with either Dex (100 nM) or diluent for $2 \mathrm{~d}$. All culture plates were then shifted to the same medium supplemented with $\left[{ }^{3} \mathrm{H}\right]$ acetate $(10 \mu \mathrm{Ci} / \mathrm{ml})$ and pulse-labeled for 10 $h$. After the labeling period, cell layers were incubated in medium containing unlabeled sodium acetate $(1 \mathrm{mM})$ for the duration of time indicated (chase). The data are expressed as the ratio created by dividing the $\left[{ }^{3} \mathrm{H}\right] \mathrm{GAG}$ or $\left[{ }^{3} \mathrm{H}\right] \mathrm{HA}$ that accumulated in Dex-treated cultures by the accumulation in control cultures. the chase incubation (data not shown), which is consistent with the previously reported absence of hyaluronidase in human skin fibroblasts (19). These data suggest that Dex inhibition is the consequence of an attenuated rate of synthesis paralleling those observations made previously of $T_{3}$ effects on GAG accumulation (10).

To compare the effect of Dex on $\left[{ }^{3} \mathrm{H}\right] \mathrm{HA}$ with that reported previously of $T_{3}$, confluent cultures were shifted to medium enriched with $10 \% \mathrm{Tx}$-Bs to which various concentrations of either Dex or $T_{3}$ were added. Both hormones inhibited $\left[{ }^{3} \mathrm{H}\right] \mathrm{GAG}$ accumulation in a dose-dependent saturable manner (Fig. 4). Dex inhibition was maximal at $10 \mathrm{nM}$, whereas that of $\mathrm{T}_{3}$ saturated at $1 \mathrm{nM}$ (Fig. 4). The magnitude of fractional inhibition by $T_{3}$ varied among individual experiments from 26 to $54 \%$.

Having defined the concentrations of both $T_{3}$ and Dex that elicited maximal responses, a study was performed in which saturating concentrations of each hormone were added both individually and together. Compared with control cultures, those treated with Dex $(100 \mathrm{nM})$ or $\mathrm{T}_{3}(100 \mathrm{nM})$ accumulated 49 and $54 \%$ less $\left[{ }^{3} \mathrm{H}\right] \mathrm{HA}$, respectively (Fig. 5). When cultures were incubated with both hormones, $\left[{ }^{3} \mathrm{H}\right] \mathrm{HA}$ accumulation was reduced by $84 \%$ (Fig. 5). Cultures incubated with both hormones invariably accumulated considerably less $\left[{ }^{3} \mathrm{H}\right] \mathrm{GAG}$ than did those incubated with high concentrations of either hormone alone. The effects of Dex and $T_{3}$ appear additive suggesting that the two hormones inhibit GAG synthesis through separate pathways.

\section{Discussion}

Skin fibroblast cultures are an established target for the action of steroid hormones. Receptors for testosterone (20), glucocor- 


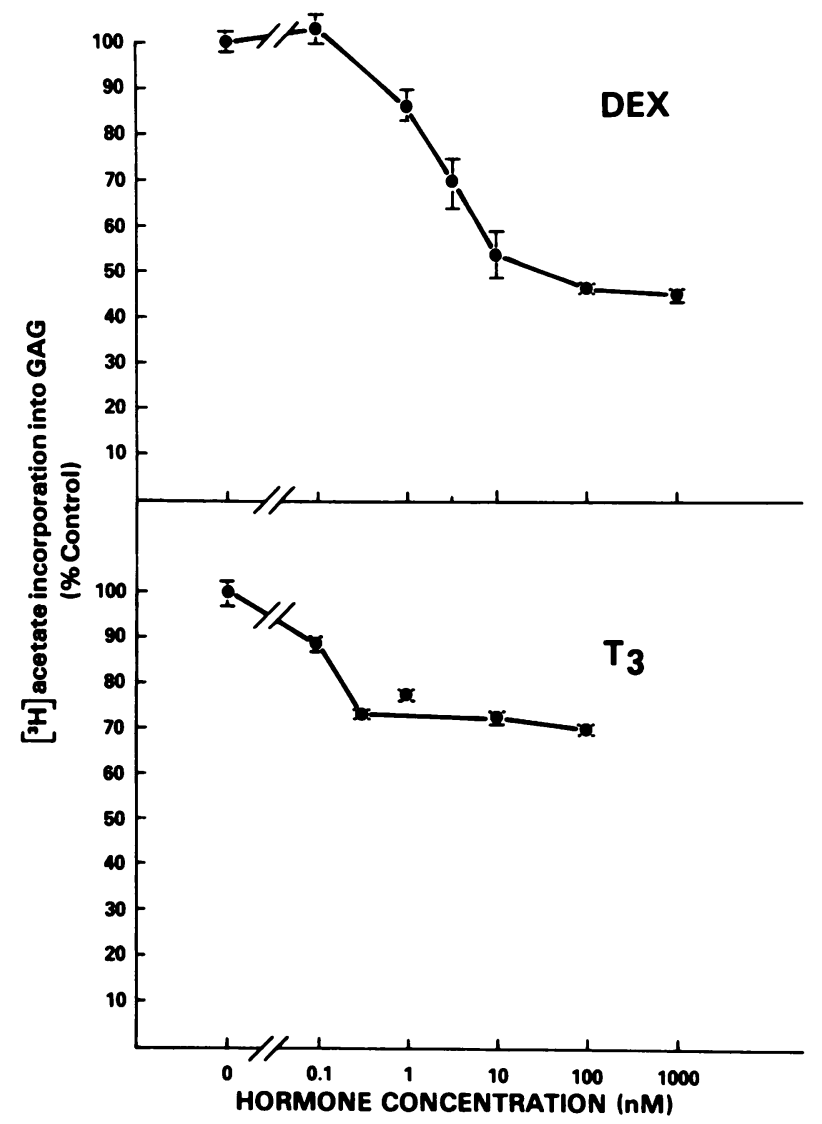

Figure 4. Effect of Dex and $\mathrm{T}_{3}$ concentrations on $\left[{ }^{3} \mathrm{H}\right] \mathrm{GAG}$ accumulation in medium supplemented with $10 \%$ thyroidectomized calf serum. Confluent cultures were shifted to medium enriched with Tx-Bs (10\%) and supplemented with various concentrations of Dex (top) or $T_{3}$ (bottom) for $2 \mathrm{~d}$. The cultures were then labeled for $24 \mathrm{~h}$ and harvested. Each datum point represents the mean \pm range of duplicate culture plates.

ticoids (21), and 1,25-dihydroxycholecalciferol (22) have been demonstrated. In addition, fibroblasts possess high affinity receptors for nonsteroidal hormones such as $\mathrm{T}_{3}(23,24)$, insulin (25), and growth hormone (26), and are known to be responsive to a variety of hormones $(27,28)$ and growth factors (29). Defects in in vitro binding and/or action in skin fibroblasts from patients with hormone resistance have been shown to reflect the clinical derangements found in vivo. These include resistance to thyroid hormone $(23,30,31)$, glucocorticoids (32), androgens (20), and vitamin D (22).

Various steroid hormones can influence GAG metabolism. Testosterone stimulates the accumulation of GAG in chick combs while hyaluronate content in surgically castrated cockerel combs falls after the discontinuation of hormone replacement (33). Similarly, estrogen enhanced the HA content in mouse skin (34). These effects could be blocked by antiestrogens such as tamoxifen and clomiphene (34). Earlier studies have demonstrated glucocorticoid inhibition of HA accumulation in various human synovial and skin fibroblasts $(14,15)$. In most of these studies, however, cultures were treated with very high concentrations of hormone (up to $100 \mu \mathrm{M}$ ), ignoring evidence that such high steroid concentrations might have nonspecific cellular effects (35). None addresses the issue of whether glucocorticoids affect GAG degradation rather than synthetic rates. The current report demonstrates that Dex, even at low concentrations ( $1 \mathrm{nM})$, can inhibit $\left[{ }^{3} \mathrm{H}\right] \mathrm{HA}$ accumulation without altering the rate of degradation. Although this effect could have resulted from intracellular precursor pool shifts, the equivalent results obtained from labeling cultures with either $\left[{ }^{3} \mathrm{H}\right]$ acetate or $\left[{ }^{3} \mathrm{H}\right]$ glucosamine suggest that this was not the case. Similarly, the lack of a Dex effect on cellular $\left[{ }^{3} \mathrm{H}\right]$ acetate uptake suggests that substrate availability was unaltered.

Stereospecificity is a hallmark of receptor-mediated hormone action. The inhibitory effects of Dex reported here are apparently quite stereospecific because two structurally related steroids devoid of glucocorticoid activity failed to alter the rate of $\left[{ }^{3} \mathrm{H}\right] \mathrm{HA}$ accumulation. Progesterone, a compound possessing both antagonistic and glucocorticoid agonistic activities at high concentrations, had no effects at concentrations which yielded near maximal Dex inhibition. At higher concentrations $(\geq 2$ $\mu \mathrm{M})$, however, progesterone did inhibit slightly $\left[{ }^{3} \mathrm{H}\right] \mathrm{GAG}$ synthesis and partially blocked the effects of Dex. These results are entirely consistent with the observations of Samuels and Tomkins that progesterone could behave both as a suboptimal inducer of tyrosine aminotransferase and as a partial antagonist of glucocorticoid induction of that enzyme in hepatoma cells in vitro (18). This result implies further that Dex inhibition of HA synthesis was mediated through glucocorticoid receptors (36)

Dex inhibition of $\left[{ }^{3} \mathrm{H}\right] \mathrm{GAG}$ synthesis in human skin fibroblasts resembles that of $T_{3}$. Because addition of both hormones in concentrations that elicit maximal responses alone inhibit accumulation further, the two hormones appear to act through separate pathways. $T_{3}$ effects were maximal at approximately one order of magnitude lower concentration than those of Dex. Thus, the relationship between concentrations of the two hormones necessary to alter the rate of HA synthesis is similar to that necessary to demonstrate effects on growth hormone synthesis in vitro (37). In addition, the Dex concentrations required to elicit maximal inhibition in these studies is well within the range shown to inhibit endogenous glucocorticoid production in vivo (38).

Glucocorticoids and $T_{3}$ are known to coregulate a number of metabolic processes. For instance, both hormones stimulate the synthesis of growth hormone messenger RNA (mRNA) in vitro (37) and apparently facilitate the effects of each other $(39,40)$. Both glucocorticoids and insulin influence $T_{3}$-mediated augmentation of malic enzyme and $\alpha$-glycerophosphate dehydrogenase in rat hepatocytes (41). $T_{3}$ and glucocorticoids in concert with testosterone and growth hormone are necessary to maintain cytosolic $\alpha_{2 u}$ globulin mRNA in the male rat liver (42). It has been reported that corticosteroids and insulin, as 


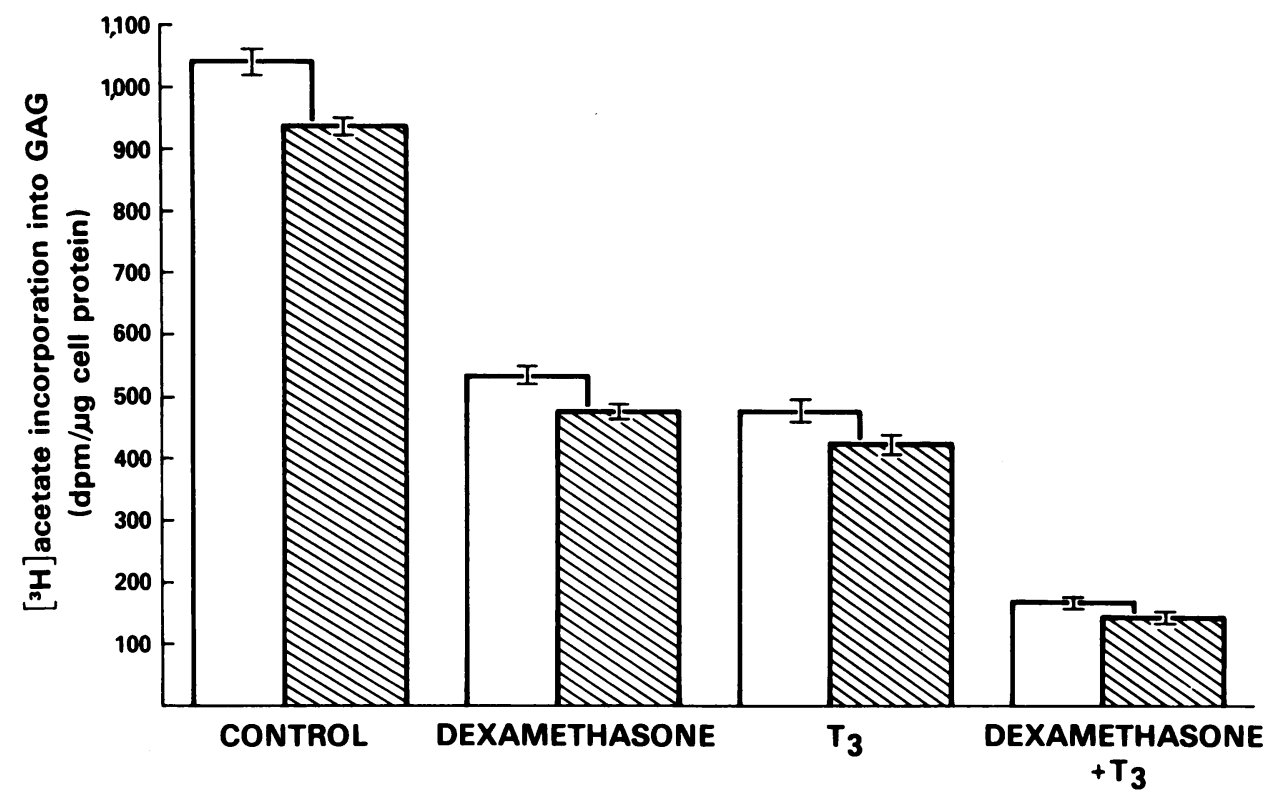

Figure 5. Comparison of Dex and $\mathrm{T}_{3}$ effects on $\left[{ }^{3} \mathrm{H}\right] \mathrm{GAG}(\square)$ and $\left[{ }^{3} \mathrm{H}\right] \mathrm{HA}(\square)$ accumulation. Confluent cultures were shifted to medium enriched with Tx-Bs (10\%), supplemented with diluent, Dex $(100 \mathrm{nM}), \mathrm{T}_{3}(100 \mathrm{nM})$, or both hormones, and incubated for $2 \mathrm{~d}$. Cultures were then shifted to identical media and labeled for $24 \mathrm{~h}$. Data are expressed as the mean \pm range of duplicate culture plates from one representative experiment.

well as thyroid hormone, exert permissive effects on the chemical and steroidal induction of $\delta$-aminolevulinate synthase in chick embryo liver cells in culture (43). A recent study described effects of both $T_{3}$ and Dex on the synthesis of specific proteins in cultured pituitary adenoma cells (44). Using two-dimensional gel electrophoresis, Ivarie and co-workers demonstrated that each hormone could affect several proteins, either by enhancing or attenuating their rate of synthesis. In addition, some proteins appeared to be coregulated by the two hormones (44). An abundance of evidence thus exists to suggest multihormonal control of specific metabolic events. Apparently, the synthesis of hyaluronate is among these.

In summary, these studies demonstrate that Dex inhibits $\left[{ }^{3} \mathrm{H}\right] \mathrm{HA}$ synthesis in fibroblasts in a similar manner to other established effects of glucocorticoids. While the precise mechanism(s) through which Dex, as well as $T_{3}$, affects GAG synthesis remains incompletely understood, these results define a shared and perhaps physiologically important role for each hormone in the regulation of macromolecular synthesis in human skin fibroblasts.

\section{Acknowledgments}

The author wishes to express gratitude to Professors E. D. Bransome, Jr. and S. Refetoff for critical review, and to Mrs. Nan Simpson for her help in preparing this manuscript. I thank Ms. B. K. Howerton for her expert technical assistance.

This work was funded in part by the Medical Research Service of the Veterans Administration. Dr. Smith is a Research Associate of the Veterans Administration Medical Research Service Career Development Program.

\section{References}

1. Lever, W. F., and G. Schaumburg-Lever. 1983. Histopathology of the Skin. J. B. Lippincott Co., Philadelphia, PA. 424-429.
2. Berenson, G. S., and E. R. Dalferes, Jr. 1965. Urinary excretion of mucopolysaccharides in normal individuals and in the Marfan syndrome. Biochim. Biophys. Acta. 101:183-192.

3. Beierwaltes, W. M., and A. J. Bollet. 1959. Mucopolysaccharide content of skin in patients with pretibial myxedema. J. Clin. Invest. 38:945-948.

4. Gabrilove, J. L., and A. W. Ludwig. 1957. The histogenesis of myxedema. J. Clin. Endocrinol. Metab. 17:925-932.

5. Hopwood, J. J., and A. Dorfman. 1977. Glycosaminoglycan synthesis by cultured human skin fibroblasts after transformation with Simian virus 40. J. Biol. Chem. 252:4777-4785.

6. Turakainen, H., H. Larjava, H. Saarni, and R. Penttinen. 1980. Synthesis of hyaluronic acid and collagen in skin fibroblasts cultured from patients with Osteogenesis Imperfecta. Biochim. Biophys. Acta. 628:388-397.

7. Lamberg, S. I., and A. Dorfman. 1973. Synthesis and degradation of hyaluronic acid in the cultured fibroblast of Marfan's disease. $J$. Clin. Invest. 52:2428-2433.

8. Saarni, H., M. Tammi, and E. Vuorio. 1977. Effects of cortisol on glycosaminoglycans synthesized by normal and rheumatoid synovial fibroblasts in vitro. Scand. J. Rheumatol. 6:222-224.

9. Smith, T. J., A. L. Horwitz, and S. Refetoff. 1981. The effect of thyroid hormone on glycosaminoglycan accumulation in human skin fibroblasts. Endocrinology. 108:2397-2399.

10. Smith, T. J., Y. Murata, A. L. Horwitz, L. Philipson, and S. Refetoff. 1982. Regulation of glycosaminoglycan synthesis by thyroid hormone in vitro. J. Clin. Invest. 70:1066-1073.

11. Ponec, M., C. de Haas, B. N. Bachra, and M. K. Polano. 1977. Effects of glucocorticosteroids on primary human skin fibroblasts. I. Inhibition of the proliferation of cultured primary skin and mouse L929 fibroblasts. Arch. Dermatol. Res. 259:117-123.

12. Ponec, M., I. Hasper, G. D. N. E. Vianden, and B. N. Bachra. 1977. Effects of glucocorticosteroids on primary human skin fibroblasts. II. Effects on total protein and collagen biosynthesis by confluent cell cultures. Arch. Dermatol. Res. 259:125-134.

13. Khalid, B. A. K., S. Gyorki, G. L. Warne, and J. W. Funder. 1983. Cystic fibrosis and normal fibroblasts have identical glucocorticoid 
receptor profiles and induced protein responses. Clin. Endocrinol. 18:407-415.

14. Mapleson, J. L., and M. Buchwald. 1981. Effect of cycloheximide and dexamethasone phosphate on hyaluronic acid synthesis and secretion in cultured human skin fibroblasts. J. Cell. Physiol. 109:215-222.

15. Saarni, H., and M. Tammi. 1978. Time and concentration dependence of the action of cortisol on fibroblasts in vitro. Biochim. Biophys. Acta. 540:117-126.

16. Lowry, O. H., N. J. Rosebrough, A. L. Farr, and R. J. Randall. 1951. Protein measurement with the Folin phenol reagent. J. Biol. Chem. 193:265-275.

17. Dische, F. 1947. A specific color reaction for glucuronic acid. J. Biol. Chem. 171:725-730.

18. Samuels, H. H., and G. M. Tomkins. 1970. Relation of steroid structure to enzyme induction in hepatoma tissue culture cells. $J$. Mol Biol. 52:57-74.

19. Arbogast, B., J. J. Hopwood, and A. Dorfman. 1975. Absence of hyaluronidase in cultured human skin fibroblasts. Biochem. Biophys. Res. Commun. 67:376-382.

20. Keenan, B. S., W. J. Meyer, III., A. J. Hadjian, H. W. Jones, and C. J. Migeon. 1974. Syndrome of androgen insensitivity in man Absence of $5 \alpha$-Dihydrotestosterone Binding Protein in skin fibroblasts. J. Clin. Endocrinol. Metab. 38:1143-1146.

21. Bruning, P. F., W. J. Meyer III, and C. J. Migeon. 1979. Glucocorticoid receptor in cultured human skin fibroblasts J. Steroid. Biochem. 10:587-593.

22. Liberman, U. A., C. Eil, and S. J. Marx. 1983. Resistance to 1,25-dihydroxyvitamin D. J. Clin. Invest. 71:192-200.

23. Bernal, J., S. Refetoff, and L. J. DeGroot. 1978. Abnormalities of triiodothyronine binding to lymphocyte and fibroblast nuclei from a patient with peripheral tissue resistance to thyroid hormone action. J. Clin. Endocrinol. Metab. 47:1266-1272.

24. Eil, C., H. G. Fein, T. J. Smith, R. W. Furlanetto, M. Bourgeois, M. W. Stelling, and B. D. Weintraub. 1982. Nuclear binding of $\left[{ }^{125} \mathrm{I}\right]$ triiodothyronine in dispersed cultured skin fibroblasts from patients with resistance to thyroid hormone. J. Clin. Endocrinol. Metab. 55:502-510.

25. Gavin, J. R., III., J. Roth, P. Jen, and P. Freychet. 1972. Insulin receptors in human circulating cells and fibroblasts. Proc. Natl. Acad. Sci. USA. 69:747-751.

26. Murphy, L. J., E. Vrhovsek, and L. Lazarus. 1983. Identification and characterization of specific growth hormone receptors in cultured human fibroblasts. J. Clin. Endocrinol. Metab. 57:1117-1124.

27. Craig, J. W., L. S. Huang, and J. Larner. 1980. Insulin stimulation of glycogen synthase activity in cultured human fibroblasts from diabetic and control subjects. Diabetologia. 18:109-113.

28. Vogelaar, J. P. M., and E. Erlichman. 1936. The growth of human fibroblasts in media containing various amounts of thyroxin. Am. J. Cancer. 26:358-367.

29. Harley, C. B., S. Goldstein, B. I. Posner, and H. J. Guyda. 1980. Insulin-like peptides stimulate metabolism but not proliferation of human fibroblasts. Am. J. Physiol. 239:E125-E131.
30. Chait, A., R. Kanter, W. Green, and M. Kenny. 1982. Defective thyroid hormone action in fibroblasts cultured from subjects with the syndrome of resistance to thyroid hormone. J. Clin. Endocrinol. Metab. 54:767-772.

31. Murata, Y., S. Refetoff, A. L. Horwitz, and T. J. Smith. 1983. Hormonal regulation of glycosaminoglycan accumulation in fibroblasts from patients with resistance to thyroid hormone. J. Clin. Endocrinol. Metab. 57:1233-1239.

32. Chrousos, G. P., A. Vingerhoeds, D. Brandon, C. Eil, M. Pugeat, M. DeVroede, D. L. Loriaux, and M. B. Lipsett. 1982. Primary cortisol resistance in man. J. Clin. Invest. 69:1261-1269.

33. Schiller, S., E. P. Benditt, and A. Dorfman. 1952. Effect of testosterone and cortisone on the hexosamine content and metachromasia of chick combs. Endocrinology. 50:504-510.

34. Uzuka, M., K. Nakajima, S. Ohta, and Y. Mori. 1980. The mechanism of estrogen-induced increase in hyaluronic acid biosynthesis, with special reference to estrogen receptor in the mouse skin. Biochim. Biophys. Acta. 627:199-206.

35. Nelson, D. H. 1980. Corticosteroid-induced changes in phospholipid membranes as mediators of their action. Endocr. Rev. 1:180199.

36. Funder, J. W., D. Feldman, and I. S. Edelman. 1973. Glucocorticoid receptors in rat kidney: The binding of tritiated-dexamethasone. Endocrinology. 92:1005-1013.

37. Martial, J. A., J. D. Baxter, H. M. Goodman, and P. H. Seeburg. 1977. Regulation of growth hormone messenger RNA by thyroid and glucocorticoid hormones. Proc. Natl. Acad. Sci. USA. 74:1816-1820.

38. Melby, J. C., and S. L. Dale. 1969. Comparison of absorption, disposal and activity of soluble and repository corticosteroid esters. Clin. Pharmacol. Therapeut. 10:344-349.

39. Martial, J. A., P. H. Seeburg, O. Guenzi, H. M. Goodman, and J. D. Baxter. 1977. Regulation of growth hormone gene expression. Synergistic effects of thyroid and glucocorticoid hormone. Proc. Natl. Acad. Sci. USA. 74:4293-4295.

40. Samuels, H. H., F. Stanley, and L. E. Shapiro. 1979. Control of growth hormone synthesis in cultured $\mathrm{GH}_{1}$ cells by 3,5,3'-triiodo-Lthyronine and glucocorticoid agonists and antagonists: studies on the independent and synergistic regulation of the growth hormone response. Biochemistry. 18:715-721.

41. Wilson, E. J., and W. C. McMurray. 1980. Insulin and cortisol increase the response of rat hepatocytes in primary culture to 3,3'5triiodothyronine. Biochem. Biophys. Res. Commun. 93:179-185.

42. Kurtz, D. T., and P. Feigelson. 1978. Multi-hormonal control of messenger-RNA for hepatic protein Alpha-2U globulin. Biochem. Actions Horm. 5:433-455.

43. Sassa, S., and A. Kappas. 1977. Induction of $\delta$-aminolevulinate synthase and porphyrins in cultured liver cells maintained in chemically defined medium. J. Biol. Chem. 252:2428-2436.

44. Ivarie, R. D., J. D. Baxter, and J. A. Morris. 1981. Interaction of thyroid and glucocorticoid hormones in rat pituitary tumor cells. $J$. Biol. Chem. 256:4520-4528. 